\title{
Steroids in pediatric acute respiratory distress syndrome
}

\author{
Nicolás Monteverde-Fernández ${ }^{1,2}$, Federico Cristiani $^{3}$, Jenniffer McArthur ${ }^{4}$, Sebastián González-Dambrauskas ${ }^{1,5}$ \\ ${ }^{1}$ Red Colaborativa Pediátrica de Latinoamérica (LARed Network), Uruguay; ${ }^{2}$ Medica Uruguaya Corporación Asistencia Médica (MUCAM). \\ Cuidados Intensivos Neonatales y Pediatricos (CINP), Uruguay; ${ }^{3}$ Department of Anesthesiology, Centro Hospitalario Pereira Rossell, Cátedra \\ de Anestesiología, Universidad de la República, Montevideo, Uruguay; ${ }^{4}$ Division of Critical Care, Department of Pediatrics, St. Jude’s Children's \\ Research Hospital, Memphis, TN, USA; ${ }^{5}$ Cuidados Intensivos Pediátricos Especializados (CIPe) Casa de Galicia, Montevideo, Uruguay \\ Contributions: (I) Conception and design: N Monteverde-Fernández, S González-Dambrauskas; (II) Administrative support: N Monteverde- \\ Fernández, S González-Dambrauskas; (III) Provision of study materials or patients: All authors; (IV) Collection and assembly of data: All authors; (V) \\ Data analysis and interpretation: All authors; (VI) Manuscript writing: All authors; (VII) Final approval of manuscript: All authors. \\ Correspondence to: Sebastián González-Dambrauskas, MD. Red Colaborativa Pediátrica de Latinoamérica (LARed Network), Cuidados Intensivos \\ Pediátricos Especializados (CIPe) Casa de Galicia, Montevideo, Uruguay. Email: sgdambrauskas@gmail.com.
}

\begin{abstract}
Acute respiratory distress syndrome (ARDS) is a complex entity with high potential for harm and healthcare resource utilization. Despite multiple clinical advances in its ventilatory management, ARDS continues to be one of the most challenging disease processes for intensivists. It continues to lack a direct, proven and desperately needed effective therapeutic intervention. Given their biologic rationale, corticosteroids have been widely used by clinicians and considered useful by many in the management of ARDS since its first description. Adult data is abundant, yet contradictory. Controversy remains regarding the routine use of corticosteroids in ARDS. Therefore, widespread evidence-based recommendations for this heterogeneous disease process have not been made. In this article, our aim was to provide a summary of available evidence for the role of steroids in the treatment of ARDS, while giving special focus on pediatric ARDS (PARDS).
\end{abstract}

Keywords: Acute lung injury, acute respiratory distress syndrome (ARDS); pediatric acute respiratory distress syndrome (PARDS); pulmonary therapies; steroids

Submitted Mar 09, 2019. Accepted for publication Jul 15, 2019.

doi: 10.21037/atm.2019.07.77

View this article at: http://dx.doi.org/10.21037/atm.2019.07.77

\section{Introduction}

Acute respiratory distress syndrome (ARDS) research has recently celebrated its $50^{\text {th }}$ birthday (1). Despite clinical advances, ARDS continues to be one of the most challenging disease processes that intensivists face in their clinical practice, causing high mortality and disabling consequences in survivors (2). Although pathophysiological similarities exist at all ages, in the last few years the pediatric critical care community has recognized that children beyond the neonatal period have their own distinctive features and deserve special focus (3-5). Children cannot be treated as little adults and ARDS in children is now known as a specific identity: pediatric ARDS (PARDS).

In 2015, the first pediatric-specific ARDS definition was developed during the Pediatric Acute Lung Injury Consensus Conference (PALICC) with an intent to address the specific characteristics of PARDS and promote a better understanding of the syndrome (6).

From a general public health standpoint, PARDS would be considered rare. One study from the US revealed an annual incidence of 12.8 cases per 100,000 (7). Another from Australia and New Zealand found an incidence of $2.95 / 100,000$ persons $<16$ years (8). Though PARDS is not as prevalent as diseases such as cancer or asthma, its high potential for harm and high resource utilization make it worthy of further study.

Thousands of children die every year in pediatric intensive care units (PICUs) from PARDS. Using PALICC diagnostic criteria, studies have shown that 
PARDS is a common reason for PICU admission (9-11). It carries high mortality in children admitted to PICUs worldwide. In a general PICU population in urban India, PARDS had a prevalence of $9.9 \%$ and mortality up to $51.4 \%$ (9). Some pediatric populations such as hematopoietic stem cell transplant recipients are at even higher risk of both, developing PARDS $(91.5 \%$ meet PARDS criteria within first week of intubation) and dying from it (60.6\% mortality) (10). To date, the largest available epidemiological study comes from the PARDS incidence and epidemiology (PARDIE) study (11). Data was gathered from 135 PICUs in 27 countries. PARDIE found that PARDS affected $3 \%$ of patients treated in PICUs and a $17 \%$ overall mortality. The mortality rate was over $30 \%$ in the most severe hypoxemic forms. It is clear than effective interventions are desperately needed for PARDS.

Management for established PARDS remains supportive, with timely identification and treatment of the underlying cause. Despite being an important disease process in the critical care field, no specific pharmacological treatment has proven to be effective in improving significant clinical outcomes. In 2015, PALICC reviewed the available pulmonary specific ancillary treatments for PARDS and concluded that pharmacological therapies commonly used in clinical practice had low quantity of scientific evidence and their routine use could not be recommended (12).

Steroids have been proposed as beneficial and widely used since ARDS first formal description by Ashbaugh et al. (13). In their landmark study, they reported steroids use in 9 of 12 patients, highlighting dramatic response in one of them, good response in another and no clinical benefit in the rest. They stated in their discussion "the value of corticosteroids probably lies in their anti-inflammatory antiedema effect".

Fifty years after this landmark Lancet study describing steroid use in ARDS, controversy remains regarding their benefit in this complex and severe inflammatory disease. The purpose of this review is to compare, and contrast published research on the use of steroids in ARDS, with special focus on PARDS. We conducted a literature search considering articles in English or Spanish from earliest available date until December 2018 using the following sources: PubMed/Medline, Google scholar, Picutrials.net and clnicaltrials.gov. We identified studies using combined terms and synonyms for steroids and ARDS and included Medical Subject Headings (MeSH) when available. Relevant additional publications were also screened manually for publications from the articles identified in the original review of databases. For analysis in this review, we prioritized prospective, randomized controlled articles (RCTs), meta-analyses and observational studies articles. Manuscripts were segregated into adult and pediatric with various categories namely pathophysiology, pharmacological properties, epidemiology, outcomes. The authors divided categories to review. A final review process was taken by all authors.

\section{Biological/pharmacological rationale of use of steroids in PARDS}

PARDS is defined as a noncardiogenic pulmonary edema characterized by an intense pulmonary inflammatory reaction, acutely developing in 12 to 48 hours in the context of a severe systemic illness resulting in hypoxemic respiratory failure (14). It is caused primarily by damage to the alveolar epithelial endothelial permeability barrier. The disruption in permeability of this membrane results in accumulation of fluid in the alveoli. Increased permeability of the alveolar capillary membrane results in protein rich neutrophilic exudate, interstitial and alveolar edema, and hyaline membranes. These pathologic abnormalities, lead to worsened gas exchange and reduced pulmonary compliance This pathophysiology in the lung occurs in the setting of dysregulated inflammation, inappropriate activity of leukocytes and platelets, and uncontrolled activation of coagulation pathways $(15,16)$.

While a regulated inflammatory response is critical to survival, a major predictor of poor outcome in ARDS patients is persistence of pulmonary and systemic inflammation after one week of lung injury. The inability to down regulate inflammatory mediator production leads to inappropriate alveolar-capillary membrane repair and impaired pulmonary gas exchange and compliance $(17,18)$. Cytokines released in PARDS stimulate the synthesis and action of cortisol by direct action on the hypothalamicpituitary-adrenal (HPA) axis and glucocorticoid receptor (GR). Studies suggest that PARDS may be associated with critical illness-related corticosteroid insufficiency. This is defined as inadequate corticosteroid activity for the severity of a patient's illness and occurs as a result of a decrease in adrenal steroid production due to dysfunction at any point in the hypothalamic-pituitary-adrenal axis or due to tissue resistance to glucocorticoids $(19,20)$.

Two cellular signaling pathways are central to the regulation of inflammation: the stimulatory nuclear factor (NF)-kB and the inhibitory GR mediated signal 
transduction cascades. In unstimulated cells, both NF-kB and GR are predominantly sequestered in the cytoplasm. The activation of NF-kB is the essential step in the experimental development of neutrophilic lung inflammation. $\mathrm{NF}-\mathrm{kB}$, bound to inhibitory proteins in the cytoplasm (I-kB), is activated by several stimuli, such as lipopolisaccharide, physical or chemical stress, and inflammatory cytokines. This activation induces translocation of NF-kB into the nucleus where it binds to the promoter regions of target genes and initiates the transcription of multiple cytokines such as tumor necrosis factor (TNF), interleukin (IL)-1, IL-6, intracellular adhesion molecule (ICAM) 1, selectin E, and other inflammatory mediators $(17,21)$. After entering the cell, corticosteroids bind to GR in the cytoplasm, with the activation of glucocorticoid-receptor (GC-GR) complex. The GC-GR complex then moves into the nucleus and promotes activation or repression of the transcription of associated genes. The GC-GR complex may also indirectly affect cell function by binding to and modulating transcription factors such as NF-kB. Corticosteroids may inhibit NF-kB activity either by directly binding to it or increasing I-kB proteins transcription $(21,22)$.

In this way, steroids counteract almost every step of the inflammatory cascade, modulating the immune response. They cause a decrease in the production of cytokines and facilitate the production of macrophage migration inhibitory factor. Additional effects of steroids contribute to the maintenance of homeostasis during severe illness. Metabolic effects, especially stimulation of gluconeogenesis and glycogenolysis, increase the availability of energetic substrates. Cardiovascular effects maintain vascular tone, potentiates the vasoconstrictor action of catecholamines and decreases the production of nitric oxide. This favors the distribution of fluids within the vascular compartment (23).

There are several conditions for which steroids effects may be beneficial in patients with PARDS: treatment of a coexistent steroid-responsive disease; treatment of inflammation early in the course of ARDS to minimize lung damage; treatment of maladaptive healing responses late in the course of ARDS to improve lung function; treating the critical illness-related corticosteroid insufficiency; and treating the inflammatory effects of mechanical ventilation $(20,21,24,25)$.

Steroids are potentially useful in PARDS. However, because of their broad mechanism of action effecting multiple systems, patients may develop multiple adverse effects. The first publications that express concern about the safety of steroids were in mid-20th century, when there has been an expansion in the use of corticosteroids in pediatrics (26,27). The main concerns were gastrointestinal bleeding; immunosuppression leading to worsening of an existing infection; metabolic effects such as hyperglycemia, retention of sodium chloride and water and loss of potassium; hypertension; psychiatric effects such as insomnia, psychosis and delirium; and decrease in growth with prolonged use. These effects may be of clinical significance in critically ill patients with PARDS (26,28-31).

Steroid use has also been implicated in acquired neuromyopathy. These drugs cause direct myotoxicity. Intensive care unit (ICU) acquired neuromuscular weakness involves dysfunction of the nerves, muscles, or both. Nerves may be functionally impaired or completely denervated and skeletal muscles can have both impaired contractility and diminished mass from a combination of decreased protein synthesis and increased proteolysis $(32,33)$. Although steroid therapy may be involved in the development of ICU-acquired neuromyopathy, there are other contributing factors such as systemic inflammation (increased inflammatory cytokine levels), organ dysfunction, use of neuromuscular blockade and general immobility while ventilated (34). Studies have failed to demonstrate steroid causality in neuromuscular weakness, as it is difficult to control all other risk factors (25).

\section{Evidence in support of corticosteroids for PARDS}

While evidence is lacking to recommend widespread use of corticosteroids in PARDS, there are hints at their utility in ill-defined subgroups of PARDS. ARDS is characterized by inflammation (18). Therefore, the use of medications known to control inflammation have been of interest for decades.

Animal data and translational studies support the rationale for the use of steroids in PARDS. Methylprednisolone given prior to collapsing one lung in a piglet model of single lung ventilation reduced inflammatory mediators in the collapsed as well as the ventilated lung (35). In a rat model of endotoxin induced ARDS given ventilator induced lung injury, rats treated with inhaled budesonide had lower levels on inflammatory cytokines in bronchial alveolar lavage fluid (BALF) compared with rats given saline. However, budesonide treated rats had higher levels of the antiinflammatory cytokine, IL-10, in BALF. Budesonide treated rats also had less histopathological changes of ARDS and improved survival compared with rats given saline (36). In a mouse model of lipopolysaccharide induced acute 
lung injury, mice given concomitant methylprednisolone had less markers of lung inflammation as evidenced by less pathophysiological changes in lung histology, less inflammatory mediators found in BALF and better markers of lung compliance. Methylprednisolone treated mice had an increased M2/M1 macrophage ratio which in turn induced more T-regulatory cells, a cell type important for its anti-inflammatory effect (37). Therefore, animal data would suggest that corticosteroids may play a role in ameliorating inflammation in ARDS which in turn would lead to improved clinical outcomes.

Adult data regarding the use of corticosteroids in ARDS has been somewhat confusing with some studies showing benefit while others did not $(38,39)$. The most positive results came from studies by Meduri et al. One of their first studies was a randomized placebo-controlled trial of adults with ARDS that had not improved by day 7 of mechanical ventilation. Subjects randomized to the treatment arm received $2 \mathrm{mg} / \mathrm{kg}$ methylprednisolone for 14 days which was then weaned slowly through day 32 (40). By study day 10 , patients in the treatment arm had reduced lung injury scores (1.7 in treatment arm vs. 3.0 in placebo, $\mathrm{P}<0.001$ ), improved partial pressure of arterial oxygen to inspired fraction of oxygen $\left(\mathrm{PaO}_{2} / \mathrm{FiO}_{2}\right)$ ratio (262 in treatment group vs. 148 in placebo arm, $\mathrm{P}<0.001)$, and better rates of successful extubation (7/16 patients in treatment arm vs. 0/8 in placebo arm, $\mathrm{P}=0.05)$. Overall mortality was less in the treatment arm as well $[0 / 16(0 \%)$ in treatment arm vs. 5/8 $(62 \%)$ in placebo arm, $\mathrm{P}=0.002]$. An ancillary study to this trial compared cytokines and glucocorticoid levels in the two groups (41). Patients who received methylprednisolone had decreased inflammatory cytokine levels compared to the control group. Peripheral blood leukocytes donated from healthy volunteers and exposed to the serum from the methylprednisolone group had progressive increases in GR activity prompting investigators to conclude that inflammation-induced glucocorticoid resistance played a role in the prolonged inflammatory response seen in patients with prolonged ARDS. The authors felt the beneficial effect of methylprednisolone in unresolving ARDS was not so much from excessive anti-inflammatory effect but was more so due to restoration of homeostasis in a system that was out of control from glucocorticoid resistance. A subsequent larger study by Meduri et al. randomized patients earlier in their course of ARDS and used a slightly different dosing regimen (42). Ninety-one adult patients with severe early ARDS ( $\leq 72$ hours) were randomized to treatment with a methylprednisolone infusion of $1 \mathrm{mg} / \mathrm{kg} / \mathrm{day}$ for up to
28 days vs. placebo. Those in the treatment arm had decreased length of mechanical ventilation [median, 5 days (range, $3-8$ days) in treatment arm vs. 9.5 days (range, 6-19.5 days) in placebo arm, $\mathrm{P}=0.002]$, decreased ICU length of stay [median 7 days (range, 6-12 days) in treatment arm vs. 14.5 days (range, 7-20.5 days) in placebo arm, $\mathrm{P}=0.007$ ], decreased ICU mortality [13/63 patients in treatment arm $v s .12 / 28$ patients in placebo arm, relative risk (RR) 1.39; 95\% confidence interval (CI), 0.98-1.96, $\mathrm{P}=0.03$ ] and a lower rate of infection (40 new infections in 63 patients in treatment arm vs. 40 new infections in 28 patients in placebo arm, $\mathrm{P}=0.0002$ ).

A subsequent ARDSnet trial randomized 180 adults with ARDS to methylprednisolone vs. placebo (43). Patients enrolled between day 7 to day 28 of ARDS. Patients randomized to the treatment arm received methylprednisolone $2 \mathrm{mg} / \mathrm{kg} /$ day for 14 days followed by $1 \mathrm{mg} / \mathrm{kg} /$ day for 7 days, then were slowly tapered off over the next several days. If patients extubated prior to the first 3 weeks, once they had tolerated extubation for 48 hours, they were rapidly weaned from corticosteroids over 48 hours. There was no difference in the primary outcome of the trial, 60-day mortality, leading the authors to conclude there was no role for steroids in ARDS. However, in closer examination of their secondary outcomes, there is data supporting the use of corticosteroids. Patients in the methylprednisolone group had a faster time to extubation (14.1 days in treatment arm vs. 23.6 days in placebo arm, $\mathrm{P}=0.006)$, increased mean ventilator free days at day 28 (6.8 \pm 8.5 days in treatment arm $v s .11 .2 \pm 9.4$ days in placebo arm, $\mathrm{P}<0.001)$, increased mean cardiovascular failure free days $(17.9 \pm 10.2$ days in treatment arm vs. $20.7 \pm 8.9$ in placebo arm, $\mathrm{P}=0.03$ ) and improved markers of lung compliance without an increased risk of infection.

Two meta-analyses were performed shortly after the previously discussed studies were completed. These showed mixed results with one showing no conclusive evidence for the use of corticosteroids in ARDS (38) while the other showed benefit in the same population (39).

Meta-analyses of steroid trials in adults with ARDS published in this decade have universally shown improved outcomes in the corticosteroid group $(44,45)$. Meduri et al. analyzed individual patient data from 4 randomized controlled trials (RCTs) of corticosteroids in adults with ARDS (45). The individual patient data was added to available aggregate data from 4 additional trials of hydrocortisone in early ARDS. This meta-analysis showed improved hospital mortality, increase in ventilator 
free and ICU free days, decreased risk of shock and no difference in nosocomial infections in the steroid group. Yang et al performed a meta-analysis of 14 available trials of glucocorticoids in adults with ARDS which included 1,441 patients ( 774 who received steroids and 667 patients in control groups) (44). Nine of the trials used low-dose steroids $(\leq 1 \mathrm{mg} / \mathrm{kg} /$ day $)$ while 3 used high dose steroids ( $\geq 2 \mathrm{mg} / \mathrm{kg} /$ day). Eleven trials began steroids in the early phase of ARDS while 2 began steroids during the late phase. Trials using low dose steroids had a decreased risk of mortality when compared to placebo (RR 0.57 ; $95 \%$ CI, 0.39-0.94; $\mathrm{P}<0.05$ ), while trials using high dose steroids did not show a mortality difference. Trials starting steroids in the early phase of ARDS showed decreased mortality compared to placebo (RR 0.37; 95\% CI, 0.16-0.86; $\mathrm{P}<0.05$ ) while those starting steroids in the late phase did not have a statistically significant difference in mortality. Five trials had data available to compare ventilator free days at day 28. Patients who received steroids had increased ventilator free days compared to placebo $(\mathrm{P}<0.05)$. There was no difference seen in nosocomial infection risk comparing the steroid group to placebo.

Pediatric data are lacking regarding the use of corticosteroids in ARDS. There are no large, randomized controlled studies of corticosteroids in PARDS to date. There have been case series and case reports describing various corticosteroid dosing regimens in diverse PARDS cases (46-50) which hint at the possibility of a favorable risk to benefit ratio, but the numbers are much too small to draw conclusions.

More recently, De Luca et al. published a study showing an association between elevated inflammatory cytokine levels in the bronchoalveolar lavage (BAL) fluid of infants with ARDS (50). Higher levels of TNF- $\alpha$ and secretory phospholipase $\mathrm{A}_{2}$ were associated with a higher severity of illness. This study brings into question whether decreasing inflammatory cytokines would improve outcomes in PARDS. As corticosteroids are known to down regulate the production of inflammatory cytokines (23), they theoretically could play an important role in controlling the pathologic inflammation of ARDS.

More recently, a randomized double-blind placebocontrolled pilot study of methylprednisolone was performed on 35 PARDS patients. Patients received placebo or methylprednisolone within the first 72 hours of mechanical ventilation (51). The methylprednisolone course was shorter than what was used in the earlier adult trials in an attempt to minimize the risk of muscle weakness due to prolonged steroid exposure. This pilot study used an initial 7 -day course at $2 \mathrm{mg} / \mathrm{kg} /$ day then tapered off over the next 7 days. The study was not powered to see a difference in outcomes, but it did show the feasibility of performing a larger more definitive study in the future. Such a trial would be important as despite the lack of data, many pediatric intensivists use corticosteroids in their patients with PARDS (52).

The group most likely to benefit from corticosteroid administration in PARDS would be those with underlying conditions that are potentially responsive to steroids such as asthma, diffuse alveolar hemorrhage, Pneumocystis pneumonia, radiation pneumonitis and other chronic obstructive lung diseases (25). Unfortunately, this group is frequently excluded from clinical trials, making evidencebased recommendations difficult.

\section{Evidence against the use of corticosteroids for PARDS}

While treatment options to improve outcomes in PARDS are desperately needed and steroids logically would seem to be helpful, the evidence derived from RCT and metaanalyses remains contradictory. There are several limitations to the available studies leaving them inadequate to make definitive recommendations. Most positive studies are led by the efforts of the Meduri group beginning in the 1980s. Arguments against the use of steroids in ARDS center around the lack of clear evidence of benefit and concern for side effects such as hyperglycemia, hypertension, immunosuppression and neuromuscular weakness, particularly when used during a long ventilatory course.

In 2015, the PALICC group recommended against the routine use of corticosteroids in children with PARDS (12). Their recommendation was based on limited pediatric data as there were no RCT in children at the time of their recommendation, only case series and case reports (46-49). Despite positive effects found in some outcomes such as ventilator free days and improved cardiopulmonary physiology, the current global recommendations are that steroids should not be used routinely in adult patients with ARDS (Table 1).

Ruan et al. performed a meta-analysis of available studies of steroids in adult ARDS (63). This meta-analysis included 18 RCTs and 10 cohort studies. The analysis of the RCTs included 725 patients with moderate heterogeneity. They showed corticosteroids had a possible, but statistically insignificant effect on ICU mortality but no effect on 
Table 1 Summary of most relevant guidelines and clinical studies of steroids in the management of ARDS (both adult and/or pediatric populations)

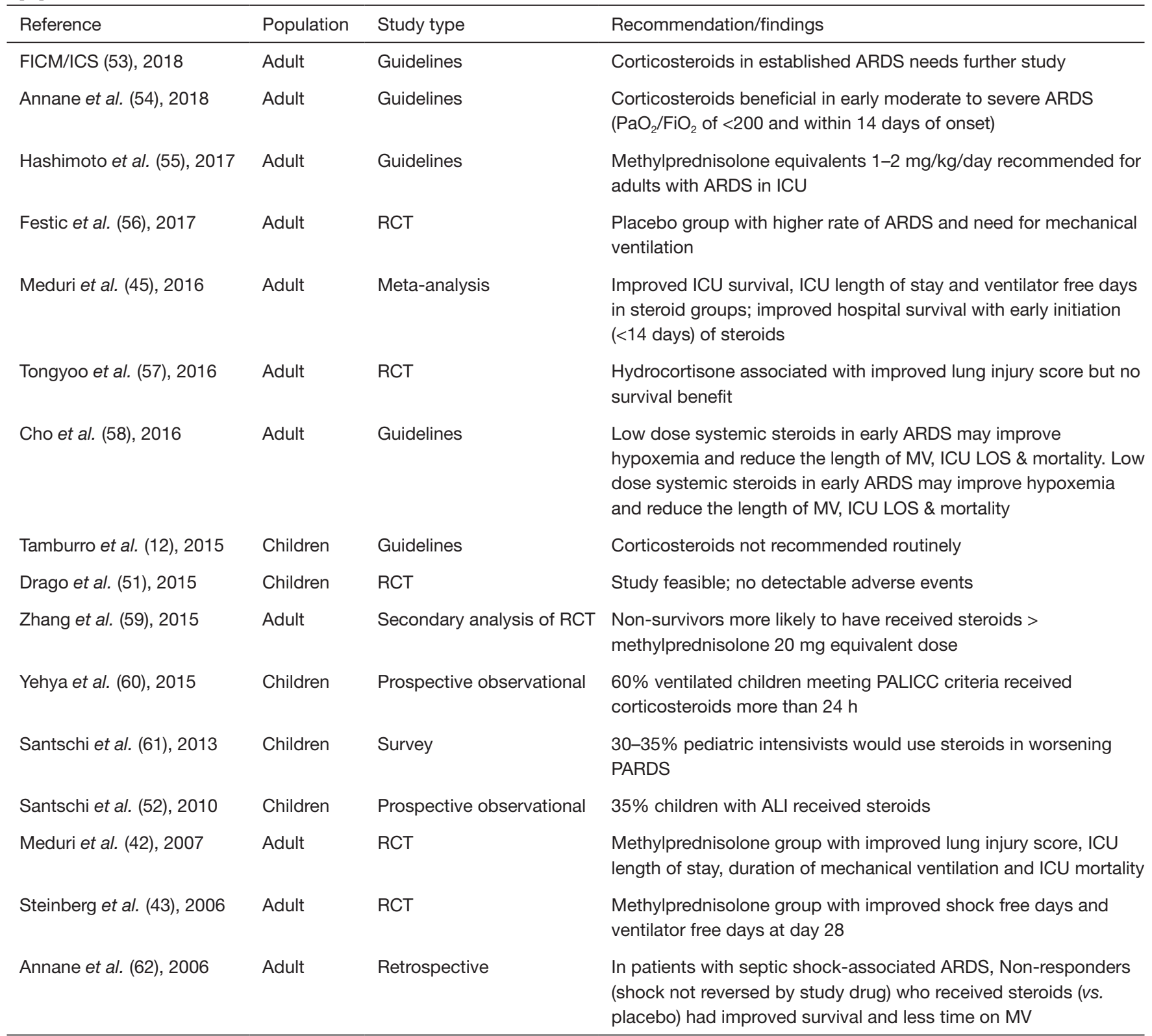

ALI, acute lung injury; ARDS, acute respiratory distress syndrome; ICU, Intensive care unit; LOS, length of stay; MV, mechanical ventilation; PARDS, pediatric acute respiratory distress syndrome; RCTs, randomized controlled trials.

60-day mortality. In the cohort studies which included 749 patients, corticosteroids had no effect on ICU mortality and a non-significant increase on 60-day mortality. When subgroups were analyzed, the results revealed that the response to steroids varied according with the etiology of ARDS and the timing of initiation of steroids. When the etiology of ARDS was considered, patients with influenza related ARDS had a higher mortality with steroid use (63). This data is particularly concerning for children since H1N1 influenza virus is known to cause particularly severe PARDS $(64,65)$.

Steinberg et al. found in the 2006 ARDSNet study that enrollment after day 13 of ARDS diagnosis was associated with a significantly higher mortality rate (43). The 
ARDSNet findings suggest that if there is any benefit to be gained from the use of steroids in persistent ARDS, that they should be started before day 14 . Zhang et al. performed a post-hoc analysis of a rosuvastatin trial in adults with ARDS (59). They compared steroid usage in 540 survivors vs. 205 non-survivors and found that use of steroids at a minimum dose of $20 \mathrm{mg}$ methylprednisolone equivalents was not associated with an effect on mortality after adjusting for confounding factors [odds ratio (OR) 1.18; 95\% CI, $0.81-1.71)]$.

Tongyoo et al. conducted a single-center doubleblind randomized, placebo-controlled trial, in 197 adult patients with sepsis-associated ARDS (57). Patients were randomized to hydrocortisone $50 \mathrm{mg}$ every 6 hours for 7 days or placebo. Hydrocortisone was associated with a significant improvement in pulmonary physiology as measured by $\mathrm{PaO}_{2} / \mathrm{FiO}_{2}$ and lung injury scores, but did not show a significant survival benefit or difference in length of mechanical ventilation.

The Meduri group has criticized these negative results. They asserted that current reviews and meta-analyzes should be limited to trials where low to moderate daily doses have been investigated such as methylprednisolone $\leq 1 \mathrm{mg} / \mathrm{kg} /$ day in early phase ARDS, or $\leq 2 \mathrm{mg} / \mathrm{kg} /$ day for late phase ARDS (45). They argued that the negative meta-analyses include early studies using very high doses of methylprednisolone or rapid tapering of steroids, both practices that are now known to lack benefit and potentially cause harm (66). Criticism for Meduri's meta-analysis is based upon potential academic bias given that he is the author of nearly half of the studies included in his metaanalysis (67).

Recent trials in children failed to show a survival benefit for corticosteroids in ARDS. Drago et al. completed the first RCT of corticosteroids in children with PARDS (51). Thirty-five PARDS patients were randomized to receive placebo versus methylprednisolone $2 \mathrm{mg} / \mathrm{kg}$ bolus followed by a continuous infusion of $1 \mathrm{mg} / \mathrm{kg} /$ day for 7 days then a slow taper over the subsequent 7 days. Patients in the steroid group had improved $\mathrm{PaO}_{2} / \mathrm{FiO}_{2}$ at day 8 and less need for oxygen at ICU transfer. However, there was no significant difference in length of ICU stay, length of hospital stay, ventilator free days or hospital mortality. The authors of this study pointed out that it was not powered to show a survival benefit and that larger studies are both feasible and necessary.

As future studies are developed to definitively answer the steroid debate in PARDS, it will be necessary to tease out the role that an individual's genetics and the underlying etiology of PARDS play in predicting their response to corticosteroid therapy. As pediatricians we can likely learn much from the studies that have already been completed in adults.

\section{What do guidelines suggest and what should clinicians do?}

As described previously, the 2015 PALICC guidelines do not recommend corticosteroids as routine therapy in PARDS (12). Their recommendation against steroid use in PARDS was unambiguous and met the "strong agreement" standard. The authors highlighted the need for future research to identify populations most likely to benefit from steroids as well as optimal dosing regimens.

In 2017, the European Paediatric Mechanical Ventilation Consensus Conference (PEMVECC), stated there were no specific recommendations on corticosteroids use in PARDS other than use in post-extubation stridor prevention (68).

Adult guidelines are contradictory and highlighted the lack of quality evidence (Table 1). Two ARDS guidelines from Asia $(55,58)$ recommend the administration of steroids for adult patients with ARDS (equivalent dose methylprednisolone $1-2 \mathrm{mg} / \mathrm{kg} /$ day). The recommendation is based upon the perceived beneficial effect of low dose steroids in early ARDS leading to lessened hypoxemia and decreased duration of mechanical ventilation, not for a reduction in mortality. The 2016 Scandinavian clinical practice guidelines recommend against the routine use of corticosteroids in any dose or duration in adults with ARDS (strong recommendation, low-quality of evidence) (69).

Recently, a task force of the Society of Critical Care Medicine (SCCM) and the European Society of Intensive Care Medicine (ESICM) published recommendations for the management of critical illness-related corticosteroid insufficiency (54). They reviewed 9 trials of prolonged administration of corticosteroids in adults with ARDS. In their review they consistently found the steroid group had decreased markers of inflammation, decreased duration of mechanical ventilation and decreased hospital mortality by $7 \%$ in mild ARDS and $11 \%$ in severe ARDS. The only risk found in the glucocorticoid group was for hyperglycemia in the first 36 hours after starting steroids. There was no increased risk of neuromuscular weakness, gastrointestinal bleeding or nosocomial infection in the steroid group compared with placebo. Patients who developed hyperglycemia did not have any increased risk of morbidity. 
Therefore, the task force recommended methylprednisolone at a dose of $1 \mathrm{mg} / \mathrm{kg} /$ day in adults with ARDS and a $\mathrm{PaO}_{2} / \mathrm{FiO}_{2}<200$ within the first 6 days of illness. After day 6 of illness, they recommend increasing the dose to $2 \mathrm{mg} / \mathrm{kg} / \mathrm{day}$. They further recommend a slow taper over at least 13 days.

The 2018 Faculty of Intensive Care Medicine (FICM)/ Intensive Care Society (ICS) Guidelines for corticosteroids use in adult ARDS were limited to research. The group recommended that corticosteroid use in established ARDS should undergo evaluation in a multicenter RCT (53).

What is recommended in guidelines is not necessarily what clinicians do. In a 2010 cross-sectional study across 59 PICUs from North America and Europe, Santschi et al. reported $35 \%$ of PARDS children received corticosteroids (52). Similar numbers emerged in a 2013 international survey of 54 PICU practitioners (47 PICUs in 11 countries). Survey respondents were asked their PARDS management in three different clinical scenarios of acute lung injury (61). Thirty percent responded that they would use steroids in PARDS. The most detailed description of steroids use in PARDS was the prospective observational single-center study by Yehya et al. (60). In their comprehensive analysis, $60 \%$ of ventilated children meeting PALICC criteria received corticosteroids for more than $24 \mathrm{~h}$. A variety of steroid regimens were reported: $51 \%$ hydrocortisone, $41 \%$ methylprednisolone, $5 \%$ dexamethasone, $3 \%$ a combination.

In our region Latin-American, there is no published data regarding current practices. We searched the LARed Network registry from May 2017 to December 2018. LARed contains data from 35 PICUs in 8 Latin-Americans countries. During the chosen time period, 3,397 children were admitted with acute respiratory failure, 319 (9.4\%) met PARDS criteria and $144(45.1 \%)$ received systemic corticosteroids.

\section{Conclusions}

Corticosteroid use in PARDS remains an important clinical question. There is a paucity of data in children to guide their use. Data from adult studies have mixed results with some studies showing clear benefit while others do not. This may be explained by radical differences in dosing regimens, patient selection and outcomes measured between trials. Due to the heterogeneous nature of PARDS, it is predictable that steroids do not achieve a homogenous therapeutic response, thus, making universal recommendations nearly impossible.

The most promising results have been in trials utilizing low to moderate doses (equivalent to methylprednisolone $1-2 \mathrm{mg} / \mathrm{kg} / \mathrm{day}$ ), begun relatively early ( $<3 \mathrm{~d}$ in the course of early ARDS, or $<14 \mathrm{~d}$ in the late ARDS) in the course of ARDS and tapered slowly over time (12 or more days). While there is not adequate evidence to recommend routine use of corticosteroids in PARDS, it is a therapy that desperately warrants further study to identify the correct patient population, timing of administration and dosing regimen.

\section{Acknowledgments}

None.

\section{Footnote}

Conflicts of Interest: The authors have no conflicts of interest to declare.

Etbical Statement: The authors are accountable for all aspects of the work in ensuring that questions related to the accuracy or integrity of any part of the work are appropriately investigated and resolved.

\section{References}

1. Pham T, Rubenfeld GD. Fifty Years of Research in ARDS. The Epidemiology of Acute Respiratory Distress Syndrome. A 50th Birthday Review. Am J Respir Crit Care Med 2017;195:860-70.

2. Sweeney RM, McAuley DF. Acute respiratory distress syndrome. Lancet 2016;388:2416-30.

3. Cornfield DN. Acute respiratory distress syndrome in children: physiology and management. Curr Opin Pediatr 2013;25:338-43.

4. Thomas NJ, Jouvet P, Willson D. Acute lung injury in children--kids really aren't just "little adults". Pediatr Crit Care Med 2013;14:429-32.

5. Im D, Shi W, Driscoll B. Pediatric Acute Respiratory Distress Syndrome: Fibrosis versus Repair. Front Pediatr 2016;4:28.

6. Khemani RG, Smith LS, Zimmerman JJ, et al. Pediatric Acute Lung Injury Consensus Conference Group. Pediatric acute respiratory distress syndrome: definition, incidence, and epidemiology: proceedings from the Pediatric Acute Lung Injury Consensus Conference. Pediatr Crit Care Med 2015;16:S23-40.

7. Zimmerman JJ, Akhtar SR, Caldwell E, et al. Incidence 
and outcomes of pediatric acute lung injury. Pediatrics 2009; 124:87-95.

8. Erickson S, Schibler A, Numa A, et al. Acute lung injury in pediatric intensive care in Australia and New Zealand: a prospective, multicenter, observational study. Pediatr Crit Care Med 2007;8:317-23.

9. Gupta S, Sankar J, Lodha R, et al. Comparison of Prevalence and Outcomes of Pediatric Acute Respiratory Distress Syndrome Using Pediatric Acute Lung Injury Consensus Conference Criteria and Berlin Definition. Front Pediatr 2018;6:93.

10. Rowan CM, Smith LS, Loomis A, et al. Investigators of the Pediatric Acute Lung Injury and Sepsis Network. Pediatric Acute Respiratory Distress Syndrome in Pediatric Allogeneic Hematopoietic Stem Cell Transplants: A Multicenter Study. Pediatr Crit Care Med 2017;18:304-9.

11. Khemani RG, Smith L, Lopez-Fernandez YM, et al. Pediatric Acute Respiratory Distress syndrome Incidence and Epidemiology (PARDIE) Investigators; Pediatric Acute Lung Injury and Sepsis Investigators (PALISI) Network. Paediatric acute respiratory distress syndrome incidence and epidemiology (PARDIE): an international, observational study. Lancet Respir Med 2019;7:115-28.

12. Tamburro RF, Kneyber MC. Pediatric Acute Lung Injury Consensus Conference Group. Pulmonary specific ancillary treatment for pediatric acute respiratory distress syndrome: proceedings from the Pediatric Acute Lung Injury Consensus Conference. Pediatr Crit Care Med 2015;16:S61-72.

13. Ashbaugh DG, Bigelow DB, Petty TL, et al. Acute respiratory distress in adults. Lancet 1967;2:319-23.

14. Sapru A, Flori H, Quasney MW, et al. Pathobiology of Acute Respiratory Distress Syndrome. Pediatr Crit Care Med 2015;16:S6-22.

15. Meduri GU, Annane D, Chrousos GP, et al. Activation and regulation of systemic inflammation in ARDS: rationale for prolonged glucocorticoid therapy. Chest 2009;136:1631-43.

16. Bhattacharya J, Matthay MA. Regulation and repair of the alveolar-capillary barrier in acute lung injury. Annu Rev Physiol 2013;75:593-615.

17. Meduri GU, Yates Ch. Systemic Inflammation-Associated Glucocorticoid Resistance and Outcome of ARDS. Ann NY Acad Sci 2004;1024:24-53.

18. Meduri GU, Headley S, Kohler G, et al. Persistent elevation of inflammatory cytokines predicts a poor outcome in ARDS. Plasma IL- 1 beta and IL-6 levels are consistent and efficient predictors of outcome over time. Chest 1995;107:1062-73.

19. Levy-Shraga Y, Pinhas-Hamiel O. Critical illness-related corticosteroid insufficiency in children. Horm Res Paediatr 2013;80:309-17.

20. Pizarro CF, Troster EJ, Damiani D, et al. Absolute and relative adrenal insufficiency in children with septic shock. Crit Care Med 2005;33:855-9.

21. Barbosa MC, Barbosa AP, Rocco PR. Corticosteroids therapy in pediatric acute respiratory distress syndrome. Rev Bras Ter Intensiva 2010;22:384-94.

22. Rhen T, Cidlowski JA. Antiinflammatory action of glucocorticoids--new mechanisms for old drugs. N Engl J Med 2005;353:1711-23.

23. Cooper MS, Stewart PM: Corticosteroid insufficiency in acutely ill patients. N Engl J Med 2003;348:727-34.

24. Halbertsma FJJ, Vaneker M, Scheffer GJ, et al. Cytokines and biotrauma in ventilator-induced lung injury: a critical review of the literature. Neth J Med 2005;63:382-92.

25. Hartmann SM, Hough C. Argument against the Routine Use of Steroids for Pediatric Acute Respiratory Distress Syndrome. Front Pediatr 2016;4:79.

26. Good RA, Smith RT, Vernier RL. Serious untoward reactions to therapy with cortisone and adrenocorticotropin in pediatric practice. I. Pediatrics 1957;19:95-118.

27. Schongut L, Cserhati E, Turai L. Complications in steroid therapy in infancy and childhood. Gyermekgyogyaszat 1959;10:225-36.

28. Sarwal MM. Out with the old, in with the new: immunosuppression minimization in children. Curr Opin Organ Transplant 2008;13:513-21.

29. Drozdowicz LB, Bostwick JM. Psychiatric adverse effects of pediatric corticosteroid use. Mayo Clin Proc 2014;89:817-34.

30. Kapadia CR, Nebesio TD, Myers SE, et al. Drugs and Therapeutics Committee of the Pediatric Endocrine Society. Endocrine Effects of Inhaled Corticosteroids in Children. JAMA Pediatr 2016;170:163-70.

31. Schwingshackl A, Meduri GU. Rationale for Prolonged Glucocorticoid Use in Pediatric ARDS: What the Adults Can Teach Us. Front Pediatr 2016;4:58.

32. Needham DM, Wozniak AW, Hough CL, et al. National Institutes of Health NHLBI ARDS Network. Risk factors for physical impairment after acute lung injury in a national, multicenter study. Am J Respir Crit Care Med 2014;189:1214-24.

33. Hough CL, Steinberg KP, Taylor Thompson B, et al. Intensive care unit-acquired neuromyopathy and 
corticosteroids in survivors of persistent ARDS. Intensive Care Med 2009;35:63-8.

34. Meduri GU, Schwingshackl A, Hermans G. Prolonged Glucocorticoid Treatment in ARDS: impact on intensive Care Unit-Acquired weakness. Front Pediatr 2016;4:69.

35. Theroux MC, Olivant A, Lim D, et al. Low dose methylprednisolone prophylaxis to reduce inflammation during one-lung ventilation. Paediatr Anaesth 2008;18:857-64.

36. Gao W, Ju YN. Budesonide Attenuates Ventilatorinduced Lung Injury in a Rat Model of Inflammatory Acute Respiratory Distress Syndrome. Arch Med Res 2016;47:275-84.

37. Tu GW, Shi Y, Zheng Y, et al. Glucocorticoid attenuates acute lung injury through induction of type 2 macrophages. J Transl Med 2017;15:181.

38. Peter JV, John P, Graham PL, et al. Corticosteroids in the prevention and treatment of acute respiratory distress syndrome (ARDS) in adults: meta-analysis. BMJ 2008;336:1006-9.

39. Tang BM, Graig JC, Eslick GD, et al. Use of corticosteroids in acute lung injury and acute respiratory distress syndrome: a systematic review and meta-analysis. Crit Care Med 2009;37:1594-603.

40. Meduri GU, Headley AS, Golden E, et al. Effect of prolonged methylprednisolone therapy in unresolving acute respiratory distress syndrome: a randomized controlled trial. JAMA 1998;280:159-65.

41. Meduri GU, Tolley EA, Chrousos GP, et al. Prolonged methylprednisolone treatment suppresses systemic inflammation in patients with unresolving acute respiratory distress syndrome: evidence for inadequate endogenous glucocorticoid secretion and inflammation-induced immune cell resistance to glucocorticoids. Am J Respir Crit Care Med 2002;165:983-91.

42. Meduri GU, Golden E, Friere AX, et al. Methylprednisolone infusion in early severe ARDS: results of a randomized controlled trial. Chest 2007;131:954-63.

43. Steinberg KP, Hudson LD, Goodman RB, et al. National Heart, Lung, and Blood Institute Acute Respiratory Distress Syndrome (ARDS) Clinical Trials Network. Efficacy and safety of corticosteroids for persistent acute respiratory distress syndrome. $\mathrm{N}$ Engl J Med 2006;354:1671-84.

44. Yang ZG, Lei XL, Li XL. Early application of lowdose glucocorticoid improves acute respiratory distress syndrome: A meta-analysis of randomized controlled trials. Exp Ther Med 2017;13:1215-24.
45. Meduri GU, Bridges L, Shih MC, et al. Prolonged glucocorticoid treatment is associated with improved ARDS outcomes: analysis of individual patients' data from four randomized trials and trial-level meta-analysis of the updated literature. Intensive Care Med 2016;42:829-40.

46. Martinot A, Fourier C, Cremer R, et al. Short-course, high-dose corticosteroid treatment in six children with late ARDS. Pediatr Pulmonol 1997;23:314-6.

47. Goh AY, Sekaran D, Roziah M. Corticosteroids rescue in late paediatric acute respiratory distress syndrome. Respirology 1999;4:295-7.

48. Guglani L, Jain S, Lodha R. Methylprednisolone therapy in a child with unresolving ARDS. Indian Pediatr 2006;43:639-42.

49. Haselton DJ, Klekamp JG, Christman BW, et al. Use of high-dose corticosteroids and high-frequency oscillatory ventilation for treatment of a child with diffuse alveolar hemorrhage after bone marrow transplantation: case report and review of the literature. Crit Care Med 2000;28:245-8.

50. De Luca D, Minucci A, Cogo P, et al. Secretory phospholipase A2 pathway during pediatric acute respiratory distress syndrome: a preliminary study. Pediatr Crit Care Med 2011;12:e20-4.

51. Drago BB, Kimura D, Rovnaghi CR, et al. Doubleblind, placebo-controlled pilot randomized trial of methylprednisolone infusion in pediatric acute respiratory distress syndrome. Pediatr Crit Care Med 2015;16:e74-81.

52. Santschi M, Jouvet P, Leclerc F, et al. PALIVE Investigators; Pediatric Acute Lung Injury and Sepsis Investigators Network (PALISI); European Society of Pediatric and Neonatal Intensive Care (ESPNIC). Acute lung injury in children: therapeutic practice and feasibility of international clinical trials. Pediatr Crit Care Med 2010;11:681-9.

53. The Faculty of Intensive Care Medicine, Intensive Care Society Guideline Development Group. Guidelines on the management of acute respiratory distress syndrome. July 6, 2018. Available online: https://www.ficm.ac.uk/ sites/default/files/ficm_ics_ards_guideline_-_july_2018.pdf (accessed Dec 10, 2018).

54. Annane D, Pastores SM, Rochwerg B, et al. Correction to: Guidelines for the diagnosis and management of critical illness-related corticosteroid insufficiency (CIRCI) in critically ill patients (Part I): Society of Critical Care Medicine (SCCM) and European Society of Intensive Care Medicine (ESICM) 2017. Intensive Care Med 2018;44:401-2.

55. Hashimoto S, Sanui M, Egi M, et al. ARDS clinical practice 
guideline committee from the Japanese Society of Respiratory Care Medicine and the Japanese Society of Intensive Care Medicine. The clinical practice guideline for the management of ARDS in Japan. J Intensive Care 2017;5:50.

56. Festic E, Carr GE, Cartin-Ceba R, et al. Randomized Clinical Trial of a Combination of an Inhaled Corticosteroid and Beta Agonist in Patients at Risk of Developing the Acute Respiratory Distress Syndrome. Crit Care Med 2017;45:798-805.

57. Tongyoo S, Permpikul C, Mongkolpun W, et al. Hydrocortisone treatment in early sepsis-associated acute respiratory distress syndrome: results of a randomized controlled trial. Crit Care 2016;20:329.

58. Cho YJ, Moon JY, Shin ES, et al. Clinical Practice Guideline of Acute Respiratory Distress Syndrome. Tuberc Respir Dis (Seoul) 2016;79:214-33.

59. Zhang Z, Chen L, Ni H. The effectiveness of Corticosteroids on mortality in patients with acute respiratory distress syndrome or acute lung injury: a secondary analysis. Sci Rep 2015;5:17654.

60. Yehya N, Servaes S, Thomas NJ, et al. Corticosteroid exposure in pediatric acute respiratory distress syndrome. Intensive Care Med 2015;41:1658-66.

61. Santschi M, Randolph AG, Rimensberger PC, et al. Pediatric Acute Lung Injury Mechanical Ventilation Investigators; Pediatric Acute Lung Injury and Sepsis Investigators Network; European Society of Pediatric and Neonatal Intensive Care. Mechanical ventilation strategies in children with acute lung injury: a survey on stated practice pattern*. Pediatr Crit Care Med 2013;14:e332-7.

62. Annane D, Sébille V, Bellissant E, et al. Effect of low doses of corticosteroids in septic shock patients with or without early acute respiratory distress syndrome. Crit Care Med 2006;34:22-30.

63. Ruan SY, Lin HH, Huang CT, et al. Exploring the heterogeneity of effects of corticosteroids on acute respiratory distress syndrome: a systematic review and meta-analysis. Crit Care 2014;18:R63.

64. Taubenberger JK, Morens DM. The pathology of influenza virus infections. Annu Rev Pathol 2008;3:499-522.

65. Streng A, Prifert C, Weissbrich B, et al. Bavarian PICU Study Group on Influenza and Other Viral ARI. Continued high incidence of children with severe influenza $\mathrm{A}(\mathrm{H} 1 \mathrm{~N} 1) \mathrm{pdm} 09$ admitted to paediatric intensive care units in Germany during the first three post-pandemic influenza seasons, 2010/11-2012/13. BMC Infect Dis 2015;15:573.

66. Meduri GU, Siemieniuk RAC. Prolonged glucocorticoid treatment in acute respiratory distress syndrome. Lancet 2017;389:1516.

67. Sweeney RM, McAuley DF. Prolonged glucocorticoid treatment in acute respiratory distress syndrome - Authors' reply. Lancet 2017;389:1516-7.

68. Kneyber MCJ, de Luca, D, Calderini, et al. section of Respiratory Failure of the European Society for Paediatric and Neonatal Intensive Care. Recommendations for mechanical ventilation of critically ill children from the Paediatric Mechanical Ventilation Consensus Conference (PEMVECC). Intensive Care Medicine 2017;43:1764-80.

69. Claesson J, Freundlich M, Gunnarsson I, et al. Scandinavian clinical practice guideline on fluid and drug therapy in adults with acute respiratory distress syndrome. Acta Anaesthesiol Scand 2016;60:697-709.
Cite this article as: Monteverde-Fernández N, Cristiani F, McArthur J, González-Dambrauskas S. Steroids in pediatric acute respiratory distress syndrome. Ann Transl Med 2019;7(19):508. doi: 10.21037/atm.2019.07.77 